\title{
Ancient Principles for the Digital Age: Truth and Ethics for Writing on the Web
}

\author{
Petra Hauptfeld \\ University of Applied Sciences Burgenland, Austria
}

\section{Abstract}

Education in 2030 will undergo huge changes with generation $\mathrm{Z}$ in the classroom. The "real digital natives" will influence economic structures as well as the educational system due to their online behaviour and increased use of technology. Teachers at the tertiary level have to be prepared for this generation, especially when integrating social media in their instruction. They have to be aware of the main differences between web writing and paper writing when it comes to blogs, wikis, eportfolios and threaded discussions in online forums. As every single person constitutes a public digital identity in social media, teachers have to know online writing competencies in order to take responsibility for their own online performance and those of their students, especially within the increasing debate of fake news. The ancient principles of truth and ethics in online media are more than ever the reliable basis for collaborative work. The EU funded project within Erasmus+, "Future-proof your classroom - teaching skills 2030", elaborates on these competencies in order to equip teachers with digital reading and writing skills in a blended-learning course.

Keywords: digital age, ancient principles

JEL classification: A20

\section{Writing on the web: a $21^{\text {st }}$ century skill}

Although several codes of conduct have been developed of how to perform on the web in a responsible way, there exists no relation between the ancient principles of truth and ethics and web performance. Recent discussions on ethics for the digital age highlight the importance of values (Spiekermann, 2019) for the web but are not referring to the ancient world. Moreover, the discussion on practical ethics focuses more on companies' accountabilities and less on writing skills by individuals performing on the web.

Writing for the web always means public writing, regardless if the information given is private or work-related. This includes a critical approach towards information, interpretation and commenting on the web, especially within the increasing debate of fake news. The paper claims that - despite new technologies the ancient philosophers offer a framework highlighting the two major principles of truth and ethics that guide online users through the still problematic digital world in terms of respect and responsibility. Especially teachers have to shape their awareness towards these values as they represent a model for their students.

The paper elaborates on the principles of truth and ethics for the web that are valid more than ever in the digital age. Ancient thinking and argumentation are deeply rooted in democratic processes and proven to be a fundamental basis. The methodology is based on an extensive desk research conducted by the University of Applied Sciences Burgenland within the project "Future-proof your classroom teaching skills 2030". The module "Writing for the web" within this blended-learning course concentrates on web writing and netiquette; highlighting the importance of 
respect, responsibility and personal rights on the web. The course is developed through the EU program Erasmus+/Strategic Partnerships, and covers essential future teaching skills within eight modules.

A coherent set of literature was developed and published by the project team of the course with contributions regarding psychological as well as digital topics. It has been discussed how technology might hinder or stimulate psychological issues in teaching (Hauptfeld, 2017b), how technology affects to a huge extent educational careers in future and how teachers will perform in the next decade (Hauptfeld, 2017a). The project team also concentrated on the creation and use of e-learning tools (Lebe and Perko, 2019) and virtual classrooms (Bigne et al., 2018). The paper aims to combine the two areas of psychology - as emotions play an essential role in web writing - and digital performance regarding the principles of truth and ethics.

The paper highlights the characteristics of web writing, followed by the consequences and at least elaborating on ancient principles and netiquette that might give an answer to the previously mentioned topics. Firstly, the paper expands on characteristics of web writing such as scanning of texts, linking and sharing information as well as liking comments. The web fosters interactivity and participation so we have to take over responsibility as well. Filter bubbles and fake news are a constant matter of discussion, moreover algorithms prefer emotional comments: Angry and aggressive blog or facebook posts are more likely to be shared than factbased information. As a consequence - the second section of the paper - emotions prevail and foster "uncivilized behaviour" and an aggressive language style. As democracy relies on the exchange of fact-based information, it is constantly endangered on the web. Ancient Greece is known as the "cradle of democracy" so the third section of the paper elaborates on the answers the Greek philosophers Socrates, Plato and Aristotle might give to establish a democratic, fair and factbased discourse online. Amongst them, truth and ethic play a major role, as well as the "right opinion" and human virtue. In his Nicomachic ethics Aristotle describes four virtues that could be applied perfectly for the web: courage, meekness, prudence and correctness. As they are timeless and proven for thousand of years they provide an ancient "code of conduct" for the web.

\section{Characteristics of web writing}

The explosive growth and dissemination of online social media has had a significant impact on teaching and learning. Teachers in future will be technical performers knowing how to integrate new technologies into existing curricula. Learning environments in the $21^{\text {st }}$ century will change permanently. Traditional and virtual classrooms will merge and using social networks is an easy and comfortable way to connect with students inside and outside class. It does not require elaborate technological skills but a profound knowledge of how to use them in a productive way. Teachers have to be aware of the main differences between online and paper-based writing (Hauptfeld and Kovalev, 2019).

One of the major differences between online and paper-based texts is the way we read them: We don't read online the same way as we do on paper. Firstly, there is the physicality of the book vs. the ephemerality of the website; when we read online, we jump from source to source within seconds, we can open hyperlinks and embed information in texts, we can share information and like comments. This all translates into a completely different reading experience. This means that online texts are structured and organised in a way that is different from paper-based ones. Eye tracking studies have shown that users' eye paths start from the upper left 
corner, moving on from there. In addition, most people don't read websites, they scan them.

According to this scanning, sharing and linking, Simanowski (2016, p. 123) claims "the loss of deep reading and deep thinking, as the likes and shares of the hyperactives do not want to excerpt or combine things but to get rid of them". Social media are not made for critical debate or fact-based arguing. As social media do not enhance reflexive communication and similarly foster everyday topics, they are not suited for political debate. Also Brodnig states (2018, p. 11) that debates on social media are rather polarized, especially in politics. The purpose is not a factbased argumentation with a proof of a statement but to harm the other parties. This process can be fostered in a negative manner by using bots or computer-generated accounts that can be bought to increase the number of likes. The more likes a comment has, the more often it is shared and commented on as for the algorithm the comment is supposed to be relevant. Public opinions can be manipulated to a huge extent for this technology-based process (elections in the US in 2016!).

On a subconscious level we assess information according to our worldview. If the given information suits our points of view, we are likely to accept it to a huge extent regardless of its truth. This process is called "confirmation bias". "That we value information more when it confirms our ideas facilitates fake news. Falsifiers can invent a statement that fits the prejudices or wishes of people - as a result these fake news are spread in the Internet" (Brodnig, 2018, p. 53). Moreover, the confirmation bias tends to create filter bubbles by reinforcing a statement, worldview or argument. "A filter bubble is the intellectual isolation that can occur when websites make use of algorithms to selectively assume the information a user would want to see, and then give information to the user according to their assumption" (Technopedia, N/A). As a result of this process diversity within discussion groups vanishes and similar worldviews are reinforced. Sceptical or critical arguments, which would enrich the debate, are missing (Brodnig, 2018, p. 66). Digital tools, subsequently, do not necessarily lead to a fact-based argumentation and exchange within a diverse setting (Brodnig, 2018, p. 71). If a different, uncomfortable worldview threatens this bubble, we are likely to react very aggressively. This can turn into massive viral outrage.

Social media largely owe their success to the fact that users enjoy relative anonymity. The lack of physical presence and invisibility lowers the users' inhibitions, making it easier to post angry and aggressive comments. In addition, filter bubbles surround users, confirming their views and beliefs. These bubbles are a bit like atoms they are charged with a lot of energy that can be positive or negative, depending on the subject matter. This explains why it is much easier to write for the web letting go of good manners.

Brodnig (2018, p. 22) states that even though fake news is not a phenomenon of the many, it is alarming as many people use social media for their news. The "Digital News Report" (2017) states that $51 \%$ of the US population consume their news via social media and are consequently more exposed to fake news. But fake news is only the tip of the iceberg - what matters most is wrong or biased information based on true incidents (Brodnig, 2018, p. 31). Claire Wardle (in: Brodnig, 2018) lists seven dangers of how to change information into half-truths: a wrong use of satire may cause damage even though this is not intended, titles or visuals do not fit to the textual information, information can be used in a fraudulent way for the purpose of insult, wrong contexts are created to influence people, fraudulent information that seems to be authentic but is a faked-up story for the purpose of fraud is published; at least fake news is created. 
According to Brodnig (2018, p. 111), fake news is problematic for two reasons: Firstly, many people do not realize that they have fallen for fake news; secondly, fake news is likely to be taken for granted if it is repeated many times. Regardless whether the information is true or not, if it is repeated often enough, the brain can easily learn wrong things (Brodnig, 2018, p. 115). This psychological process is called the "illusory truth effect": So it is of utmost importance to be sceptical and to repeat true information as well.

The Internet has answers to everything - at least that is our impression. Every day billions of queries are entered into web search engines such as Google, and more and more data is being made available to the public. In fact, searching is the most common activity on the Internet after email: almost all users search for things. It's important to keep the following in mind: The Internet remembers everything - even information that has been deleted. This is because all search engines store data in caches. So think before you write for the web. The only way to have information permanently removed is through a legal process.

\section{Consequences when writing for the web}

Social media sites are great tools but like all new technologies people need to learn how to use them properly. Their most significant challenges and the most notable risks arise from their democratic nature. On the one hand, they allow people to initiate political change and to express their opinions freely. On the other hand, they can produce aggressive behaviour and writing style towards people with opposite attitudes.

\section{Emotions prevail}

As Milborn (2018, p. 120) states, people who insult others on the web do not expect to be confronted with a "real" person, so they tend to be more aggressive when defending their opinions. Simanowski $(2016$, p. 17) askes, how capable people are to respect each other and to accept the otherness beyond simple likes, shares and clicks. Moreover the algorithms select the information that will be part of the newsfeed, so a unique worldview is created within certain filter bubbles. Emotions play an essential role in this process as angry people click more (Brodnig, 2018, p. 39) and the algorithms rank emotional comments higher than informative ones (Milborn, 2018, Brodnig, 2018). Emotions motivate people to engage in the debate but become problematic when they are targeted towards a certain group of people in the role of scapegoats. Political parties use this strategy to raise anger against a group of people to maximize attention. So it is essential that each user relies on diverse sources of information before publishing a comment, otherwise filter bubbles create a worldview that only supports the users' own thoughts and arguments which are then taken for granted.

\section{Democracy at stake}

Milborn outlines five topics (2018), which are crucial for writing on the web: Filter bubbles create a world full of like-minded persons. However, democracy only works in the public space, like the ancient (!) agora, where arguments are discussed and public opinion emerges from this process. Citizens are given the possibility to develop their opinion according to this public discourse and the web in the very beginning has had the democratic potential for this public exchange. But, secondly, it turned out on the other hand, that the web fosters and supports extreme and emotional positions within the filter bubbles. Instead of offering a wide range of ideas and 
distributing knowledge in a responsible manner, algorithms value profit-oriented emotional and one-sided information. This seems to be contradictory to the idea of the web as democratic media. A democratic process relies on reasoning and arguing and not on emotional and hateful one-sided argumentation. Thirdly, fake news, threatening statements and hateful postings gain more interest than well thought-out arguments. This leads to a process in which entire groups of people that do not want to join the emotional majority are excluded from the discourse on the web. If a person gets into the centre of a hateful online debate, this person may also be threatened in real life (murdering of Jo Cox!). As long a social media - in the fourth place according to Milborn - do not obtain the status of legal media, fake news and public lies can be distributed without any consequence. A study from MIT stated that lies reach readers six times quicker than true stories. Within filter bubbles, lies can generate conspiracy theories that spread fake news quicker than the truth. Fifth, a precious good like public opinion can be influenced very easily with bots and troll armies, "networks of politically motivated and paid users, who direct or destroy discussions with a huge number of accounts after secret agreement" (Milborn, 2018, p. 148). The advantage of a public and democratic discourse very quickly turns into the contrary when trolls are active (Wanhoff, 2011, p. 139). If a discussion escalates, users should always keep in mind that their comments, although initiated by trolls, will be read by others as well.

\section{"Uncivilized" language and behaviour}

What is interesting to know is that as early as in the year 1974, sociologist Richard Sennett predicted in his work "The Fall of Public Man" (Sennett, 2004) that the public sphere will vanish in favour of psychological and individual self-presentation. He argues that this will result in an "uncivilized" society in which public discourse is based on personal feelings. Also, Baver (2018, p. 82) states that what we perceive as "authentic" is linked to a natural, personal behaviour that contradicts a cultural one. Social media seem to accelerate this "uncivilized" process when using a "natural" language style in public including aggressive, rude or "uncivilized" phrasing. What seems to be mixed up by social media users is the distinction between the contents and the phrasing. Even if social media are meant to be a sphere for the personal exchange of information, the language style has to be more professional than in face-to-face communication. Social media are per se created for personal exchange, not claiming true information (Wanhoff, 2011, p. 125), but this does not mean to let go of good manners. What one would say to a close friend may be harmful on social media as written or spoken language is not the same means of communication. If private topics become public, identity is always at stake, "Too much of authenticity produces ethic problems in media" (Beck, 2012, p. 65). Moreover, the web stores data years beyond their publishing so one is well advised to think of the risks of abuse of information. The core of social media is to enhance discussion, but from the distance it is easier to become aggressive and threatening. Within this, especially cyber bullying is a serious problem. It is defined as an aggressive intimidating behaviour towards a respective person. The behaviour is not a new virtual phenomenon but, on the web, it causes more serious damage to the person as cyber bullying becomes public and widespread (Wanhoff, 2011, p. 168).

\section{Ancient principles and netiquette}

Taking the consequences into account, it is of the utmost importance to create respectful communication and a safe learning environment for teachers and 
students. An appropriate professional approach with fact-based information and clear guidelines for communication and writing for the web is inevitable. As stated in the introduction, the web is a new technology that requires a special netiquette for social media. It is essential because no "model for tolerance" (Simanowski, 2016, p. 18) exists within this new technology. However, which principles should web users rely upon? Going back in history, the Greek philosophers Socrates, Plato and Aristotle provide timeless values, that are valid more than ever for our technological world: Amongst them, truth and ethics play an essential role when writing for the web.

Plato's cave Allegory (introduction, in Rehn, 2005) highlights ethical norms, as one has to strive for the highest knowledge in order to take care of the welfare. Due to Plato, this attitude is not a preference but a duty for a public function. Who knows about existence, knows about the truth - knowing the truth means knowing justice and beauty and living according to these principles. As a consequence, knowledge and action are not separated. On the contrary, a misleading way of life according to Plato would be to follow a single absolute worldview (introduction, in: Rehn, 2005). Filter bubbles reinforce this single worldview, supported by algorithms. So how would algorithms look, for instance, if they were programmed according to diversity and not similarity? Brodnig (2018, p. 180) suggests a "surprise me-button": When clicked, a user could see each day a comment they would not have been confronted with before. Brodnig refers to Natalie Stroud who did a very interesting experiment, changing the "like button" into a "respect button" (Brodnig, 2018, p. 18). As a result, the behaviour of users changed such that people who made diverse statements were perceived more positively - only by changing a word!

In addition, Plato's principle of the Good does not refer to an abstract entire cosmos but to an existence that knows about the Good and the Truth and, moreover, actively implements it in life. Knowledge, deriving from active discourse (Socrates), and not from a single perception of the world, is the impulse for taking (political) action. Comparing Plato's Allegory with the filter bubbles in social media, users have to be aware of the fact that their worldview is not the only approach creating knowledge. According to Plato, every single person is obliged to strive for the highest knowledge, which means to actively engage in discourse. In doing so, users have to act according to this reflexive and self-aware constitution of knowledge. This would also minimize aggressive behaviour and harm to others. Plato refers to this attitude and behaviour as a duty. When participating in social media, this duty would enhance more reflective and diverse writing.

Plato's Menon refers to the importance of human virtue (Greek: Areté), including all positive attitudes of a person. Socrates is discussing with the army commander Menon the complicated trait of human virtue without providing an ultimate definition. Contradictory to the attitudes of health or strength, virtue is a praiseworthy habitus that also includes elements of acceptance (conclusion, in Ebert, 2019, p. 139) by the social environment. Therefore virtue might be perceived in different ways according to the respective environment. Social media per se were created for exchange within a special community, interconnection and mutual support. These positive goals can only be performed when the social environment accepts users. This means to use language in a reflexive way, including arguing and reasoning, and to provide information under the aspect of knowledge constituted either from insight or personal experiences.

Socrates also introduces the principle of the "right opinion" (Menon, 97b,c; $98 \mathrm{~b}, \mathrm{c}, \mathrm{d})$. Acting in the right way according to this principle is equal to acting out of insight. The right opinion is not worse than knowledge and not less useful for taking action. Both of them, right opinion and insight, are not naturally given but have to be 
acquired. Having a look at social media there is often a battle on "right opinions", which directly leads to the question of ethical behaviour. So it is essential on the web to rely on fact-based knowledge (based on insight or right opinion) and to determine the truth of news by checking its sources.

Aristotle characterizes in his Nicomachean Ethics several virtues. Amongst them, courage (Gigon, 1972) plays an essential role as it is in the midst between fear and confidence. When communicating on social media, it is essential to correct false information or fake news. So courage is a precondition when fighting fake news. Users have to have the confidence to contradict false information. Brodnig (2018) suggests some measures to fight fake news and false information. Firstly, she recommends being sceptical of images and checking them via images.google.com or tineye.com. As visuals are a powerful instrument, she also gives recommendations to use them in reverse to demonstrate the accuracy of an information or comment. Moreover, on websites, the "About us" page should always be visited in order to check the reliability of the site. Although sites may look very professional, they can turn out to be a fake.

Prudence (Gigon, 1972) in its positive sense is in the range of a virtue for its ability to balance desire and to value reasonable behaviour. Prudence could be a leading principle for the communication style on the web. If a person is prudent, he or she reflects on the contents of the information given, on the style and on the consequences when doing so. Asked for ethical norms in diverse codes of conduct for the web, prudence appears in several ways. Koh et al. (2005) suggest four ethical norms, deriving from a non-representative online survey, like truth of a report (fairness, balanced opinions, completeness), accountability (to take responsibility for the results), minimizing harm towards third parties and correct attribution of ownership rights including citation. Also Wanhoff (2011, p. 136) states that one has always to consider the consequences when publishing personal information and activities. Also, the EU parliament suggested in 2017 several values that have to be taken into account for IT and robotics, like security, liberty, privacy, dignity and accountability (European Parliament, 2016).

Meekness (Gigon, 1972) is a virtue related to anger. The one who shows anger at the right time will be praised, a lack of anger will be criticized, as one does not take action where they should; so these people will be perceived as simple-minded: "It is slavish to put up with abuse." (Gigon, 1972). Bitter people are hard to reconcile as they keep their passion for themselves. They have to take revenge to put an end to their anger and if this does not happen, they are permanently under pressure (Gigon, 1972). This describes perfectly how aggressive behaviour, cyber bullying and shit storms on the web work. Meekness could be a way of showing anger in a productive manner in between aggressiveness and restraint. As angry people click more and emotions are ranked higher by algorithms it is essential according to Brodnig (2018) to mistrust one's own emotion: If a comment stimulates anger or supports the own worldview to a huge extent, the comment, information or news should be checked, as falsifiers are phrasing news that is emotionally supporting. Giving explanations is also an instrument to correct fake news. Confronting others with the opposite view will likely cause a discussion, while giving explanations is less confronting and more clarifying. This does not mean not to engage in an opinionbased discourse, but to respect the inhibition threshold at all accounts.

Another important virtue is correctness (Gigon, 1972). Correctness according to Aristotle is the midst between truth and untruth. If one is conceited, he or she shows attitudes that he or she does not have; the one who negates his or her attitudes becomes ironic. The right way is in the midst of ethics, demonstrating attitudes and 
capabilities without exaggerating or underestimating them. According to this description, correctness on the web would lead to an acceptance of other opinions without defending one's own opinions as absolute truth or not trusting in one's own opinions at all. Especially commercial bloggers are interested in this more correct, "civilized" (Sennett!) media use for a better reliability and reputation. Several codes of conduct and guidelines exist for this regulation that can be summarized as following (Haeusler, 2005; Kuhn, 2005): respecting the privacy of others (no publishing of personal data without their agreement), citing sources and respecting ownership rights, using real names and identities, staying friendly (also when the discussion becomes rude), answering questions and asking for patience, accepting feedback and respecting individual emotions, humour and weaknesses. Tim O'Reilly (2007) votes for the general rule that one should not write anything that he or she won't say in person. If we have a closer look at these rules, they also apply to the real world, not only the virtual one. However, what may be underestimated is the long-term effect on the web.

\section{Conclusions}

In this paper we elaborated on the necessity of truth and ethics for the web. Ancient philosophers like Socrates, Plato and Aristotle provide timeless principles proven for thousand of years for the digital age. Combined with recent "codes of conduct" for the web they create a robust framework paving the way through the online world.

Previous research has shown that neither psychological or philosophical topics nor digital tools and virtual spaces when applied separately give an answer to the important question of correct behaviour on the web. Only the integration of the two worlds - digitally and mentally - give solutions on this essential topic.

It is of utmost importance as technology rapidly changes the way we think, communicate, work and learn together. It is essential in this process that people may not stay behind but make use of this technology that has to submit to the needs of people. However, the web started to spread around 1995 - ancient philosophers are dated back 450 before Christ - due to their timeless and proven values they provide answers also for the web.

The results of this paper are based on literature review and desk research. Studies and surveys have already shown how users perceive the web and how they behave online. Further research should concentrate on interdisciplinary work between philosophers and social scientists, especially from the area of business studies. Only mutual work between humanities and social sciences generate results of how to implement and use technology in a responsible way.

\section{References}

1. Baver, T. (2018), Die Vereindeutigung der Welt, Über den Verlust an Mehrdeutigkeit und Vielfalt, Reclam, Stuttgart.

2. Beck, K. (2012), "Neue Medien - alte Probleme? Blogs aus medien- und kommunikationsethischer Sicht", in Zerfaß, A., Welker, M., Schmidt, J. (Eds.),

Kommunikation, Partizipation und Wirkungen im Social Web, Band 1: Grundlagen und Methoden: Von der Gesellschaft zum Individuum, Köln, Halem, pp. 62-77.

3. Bigne, E., Andreu, L., Ruiz, C., Badenes, A. (2018), "Virtual classroom: Beyond brickand-mortar learning", in the Proceedings of INTED conference, Valencia, Spain, INTED.

4. Brodnig, I. (2018), Lügen im Netz. Wie Fake News, Populisten und unkontrollierte Technik uns manipulieren, 2. Auflage, Wien, Brandstätter.

5. Ebert, T. (2019), Platon: Menon, Berlin, De Gruyter. 
6. European Parliament (2016), "European Civil Law Rules in Robotics", available at: http://www.europarl.europa.eu/RegData/etudes/STUD/2016/571379/IPOL_STU(2016)5 71379_EN.pdf (29 April 2019).

7. Gigon, O. (1972), Aristoteles: Die Nikomachische Ethik, 2. Auflage, München, dtv.

8. Haeusler, J. (2005), "Zeit für eine Blog-Etiquette", available at: http://www.spreeblick.com/blog/2005/08/08/zeit-fur-eine-blog-etiquette/ (29 April 2019).

9. Hauptfeld, P., Kovalev, M. (2019), Module "Writing for the web" within the EU project "Future-proof your classroom - teaching skills 2030".

10. Hauptfeld, P. (2017a), "Reinventing educational careers in future - how teachers will perform in the next decade", in the Proceedings of ICERI conference, Sevilla, Spain, ICERI.

11. Hauptfeld, P. (2017b), "Technology meets psychology: Teaching business students critical thinking", in the Proceedings of ENTRENOVA conference, Dubrovnik, Croatia, ENTRENOVA.

12. Koh, A., Lim, A., Soon, N. E., Detenber, B. H., Cenite, M. (2005), "Ethics in blogging", available at: http://unpan1.un.org/intradoc/groups/public/documents/apcity/unpan026247.pdf (29 April 2019).

13. Kuhn, M. (2005), "C.O.B.E. A proposed Code of Blogging Ethics", available at: https://rconversation.blogs.com/COBE-Blog\%20Ethics.pdf (29 April 2019).

14. Lebe, S., Perko, I. (2019), "Supporting the creation and use of e-learning tools", Book of abstracts of the 2nd International Scientific Conference: Teaching Methods for Economics and Business Sciences, Maribor, Slovenia.

15. Milborn, C., Breitenecker, M. (2018), Change the Game, Wie wir uns das Netz von Facebook und Google zurückerobern, Wien, Brandstätter.

16. O'Reilly, T. (2007), "Call for a Blogger's Code of Conduct", available at: https://web.archive.org/web/20070409153021/http://radar.oreilly.com/archives/2007/ 03/call_for_a_blog_1.html (29 April 2019).

17. Rehn, R. (2005), Platons Höhlengleichnis, Das Siebte Buch der Politeia, Mainz, Dieterich.

18. Sennet, R. (2004), Verfall und Ende des öffentlichen Lebens. Die Tyrannei der Intimität, 14. Auflage, Frankfurt am Main, Fischer.

19. Simanowski, R. (2016), Facebook-Gesellschaft, Berlin, Matthes \& Seitz.

20. Spiekermann, S. (2019), Digitale Ethik. Ein Wertesystem für das 21. Jahrhundert, München, Droemer.

21. Technopedia (N/A), Definition of the filter bubble, available at: https://www.techopedia.com/definition/28556/filter-bubble (29 April 2019).

22. Wanhoff, T. (2011), Wa(h)re Freunde. Wie sich unsere Beziehungen in sozialen OnlineNetzwerken verändern, Heidelberg, Spektrum.

\section{About the author}

Petra Hauptfeld, Dr., is professor at the University of Applied Sciences Burgenland in the Department Business Studies with special expertise in language teaching, academic writing, intercultural communication and organizational leadership. She is an expert in international project management of EU projects (AWO - Academic Writing Online, 2014 - 2016; TEACHING 2030, 2017 - 2020) and published a number of scientific papers in international as well as national journals and participated in many conferences on future teaching and technological education, her recent areas of research. The author can be contacted at petra.hauptfeld@fh-burgenland.at. 